\title{
Determination of Sun Protective Factor of Selected Medicinal Plants from Western Nepal
}

\author{
Suman Prakash Pradhan', Kapil Adhikari', Saroj Nepal' ${ }^{2}$ Bishnu Prasad Pandey ${ }^{* 1}$ \\ ${ }^{1}$ Department of Chemical Science and Engineering, Kathmandu University, Dhulikhel, Kavre, Nepal \\ ${ }^{2} \mathrm{H}$ Plant Private Limited, Sanepa, Lalitpur, Nepal \\ "Corresponding E-mail: bishnu@ku.edu.np
}

(Received: March 2, 2020; Revised: May 6, 2020 \& Accepted: May 28, 2020)

\begin{abstract}
Plant extracts contain active ingredients that can absorb, reflect or scatter the sunlight, depending on their nature. The effectiveness of plant extracts as a skin protective agent can be determined by measuring the sun protection factor (SPF). The main aim of this study was to investigate the potential of selected medicinal plant extracts as a component in sunscreen production in modern cosmetics. The absolute methanol extract of six medicinal plants namely; Asparagus racemosus, Bergenia pacumbis, Melia azedarach, Murraya koenigii, Pleurospermum benthamii, and Thymus linearis were examined in-vitro for their sun protective ability by ultraviolet-visible spectrophotometry method with the application of Mansur equation. Our results revealed that most of the plant extracts possess prodigious SPF values as compared with commercial sunscreen. The greatest SPF value was found in P. benthamii (34.97 \pm 0.25$)$, T. linearis $(24.98 \pm 0.60)$, and B. pacumbis $(24.02 \pm 0.15)$. These results show that these plant extracts can act as a very good antisolar agent.
\end{abstract}

Keywords: Medicinal plant extracts, sun protective factor, degradation

\section{Introduction}

Acute and chronic exposure of human skin to ultraviolet (UV) radiation can causes skin damages, oxidative stress, and photoaging depending on the exposure amount and form of the UV radiation [1-3]. Although the melanin acts as the skin natural sunscreen, excessive radiations of sunrays are vulnerable and leading to skin-related complications [4]. More than one million people worldwide are suffered from skin cancer and losses their life from malignant cancer every year $[5,6]$. Nowadays, various forms of sunscreen products are available commercially with synthetic agents for protection against UV exposure. However, synthetic agents have adverse effects on skin and human health due to its toxicity. Herbal based sun protective products have increasing demands owing to its less toxicity. Secondary metabolites produced by medicinal plants and herbs have great tendencies to absorb ultraviolet radiation hence protect skin from damage [7]. Sunscreens have been used for the prevention and treatment of sunburn but several studies have shown that they are not effective in preventing premature aging and skin-related complications [8,9]. Since reactive oxygen species (ROS) is the main causing factor for photoaging and skin cancers, an effective sunscreen should contain antioxidant agents in addition to sunblock agents to be effective in the prevention of photoaging and skin cancer [10,11].

The long-term exposure to solar radiation deteriorates the elastin fibers within the extracellular matrix which leads to a premature decrease in the skin flexibility and natural ability of the skin to repair itself [12]. These days, numerous products of creams for dermal protection such as moisturizers, sunscreens, and lotions are incorporated in the modern cosmeceutical which helps to reduce the chance of the harmful effects of UV radiation in the skin. Although sunscreen blocks UV-A and UV-B to a greater extent and is important for the prevention of negative effects of sun exposure 
[13], the growing use of chemicals in it spreads detrimental consequences in peoples' health. So, plant-based sunscreen has been gaining attention in modern cosmetics to counter these problems [14-16]. In this study, our investigation finds out the potency of Nepalese herbal medicinal plants as a skin protective agent; Asparagus racemosus Willd., Bergenia pacumbis (Buch.-Jam.ex D. Don), Melia azedarach L., Murraya koenigii (L.) Spreng., Pleurospermum benthamii (DC.) C.B. Clarke, and Thymus linearis Benth. from Nepalese origin which are being used to treat skin-related complications from traditional medicine practice [17-22].

\section{Materials and Methods}

Plant collection, authorization and extract preparation The respective plant species and plant parts were collected from Humla and Mugu District of Karnali Province and Banke district of Province 5 of Nepal and scientifically authorized in National Herbarium and Plant Laboratory (KATH) Godawori, Lalitpur, Nepal (Table 1).

\begin{tabular}{|c|c|c|c|c|}
\hline $\begin{array}{l}\text { Plant } \\
\text { code }\end{array}$ & $\begin{array}{l}\text { Plants } \\
\text { (Family) }\end{array}$ & $\begin{array}{l}\text { Vernacular } \\
\text { name }\end{array}$ & Collection parts & Traditional uses \\
\hline ST1 & $\begin{array}{l}\text { Asparagus racemosus Willd. } \\
\text { (Asparagaceae) }\end{array}$ & Ban Kurilo & Rhizomes & $\begin{array}{l}\text { reported to be used for treatment of skin } \\
\text { diseases and stomach problems }[20,21]\end{array}$ \\
\hline ST2 & $\begin{array}{l}\text { Bergenia pacumbis (Buch. -Jam. } \\
\text { ex D. Don) (Saxifragaceae) }\end{array}$ & Pakhanved & Rhizomes & $\begin{array}{l}\text { used for the treatment of stomach } \\
\text { problems, fever, cough, cold, and urinary } \\
\text { problems [18] }\end{array}$ \\
\hline ST3 & $\begin{array}{l}\text { Melia azedarach L. } \\
\text { (Meliaceae) }\end{array}$ & Bakaina & Leaves & $\begin{array}{l}\text { effective against treatment of skin } \\
\text { disease, circulatory system disorder, } \\
\text { fever, and dental problems [22] }\end{array}$ \\
\hline ST4 & $\begin{array}{c}\text { Murraya koenigii (L.) Spreng. } \\
\text { (Rutaceae) }\end{array}$ & Kadipatta & Leaves & $\begin{array}{l}\text { traditionally used for Skin diseases, } \\
\text { stomach problems, and urinary tract } \\
\text { infection [17] }\end{array}$ \\
\hline ST5 & $\begin{array}{l}\text { Pleurospermum benthamii (DC.) } \\
\text { C.B. Clarke (Apiaceae) }\end{array}$ & Gandhaino & Rhizomes & $\begin{array}{l}\text { used for stomach problems, cough, cold, } \\
\text { and headache [21] }\end{array}$ \\
\hline ST6 & $\begin{array}{l}\text { Thymus linearis Benth. } \\
\text { (Lamiaceae) }\end{array}$ & Ghodamarcha & Leaves & $\begin{array}{l}\text { effective for the treatment of stomach problems, } \\
\text { cough, cold, and eye infection [19] }\end{array}$ \\
\hline
\end{tabular}

The plant materials were dried at room temperature and made powdered by grinding in electrical grinder. Five-gram powder of each samples were macerated with $50 \mathrm{~mL}$ of $100 \%$ methanol and kept overnight on rotary shaker (JEIO TECH, South Korea) at 150 $\mathrm{rpm}$ at $25^{\circ} \mathrm{C}$. On the next day, entire mixture was filtrated and concentrated to dryness by evaporating on vacuum evaporator (hanil Modul 4080C, South Korea). The extracted crude samples were kept in air tight glass vial and stored at $4{ }^{\circ} \mathrm{C}$ until use.

\section{Determination of in-vitro Sun protective factor (SPF)}

The plant extracts were dissolved in methanol (HPLC grade) to prepare the concentration of $0.5 \mathrm{mg} / \mathrm{mL}$ and scanned from $\lambda=290$ to $320 \mathrm{~nm}$ in a UV-Visible spectrophotometer (UV-1800, SHIMADZU). The commercial sunscreens of $\mathrm{SPF}=30$ was used as standard. The SPF was evaluated by an equation proposed by Mansur et al. [23].

$$
S P F=\mathrm{CF} X \sum_{290}^{320} E E(\lambda) X I(\lambda) X a b s(\lambda)
$$

In above equation, $\mathrm{CF}=10$ (Correction factor), $\mathrm{EE}(\lambda)=$ Erythemogenic effect of radiation at wavelength $\lambda$, I $(\lambda)=$ Intensity of solar light at wavelength $\lambda$, and abs $(\lambda)=$ Absorbance of wavelength $\lambda$ by a solution of the preparation.

Table 2: The normalized product function used in the

\begin{tabular}{cc}
\multicolumn{2}{c}{ calculation of SPF data } \\
\hline Wavelength $(\boldsymbol{\lambda} \mathbf{~ n m})$ & EE $\mathbf{~ I ~ ( n o r m a l i z e d ) ~}$ \\
\hline 290 & 0.0150 \\
295 & 0.0817 \\
300 & 0.2874 \\
305 & 0.3278 \\
310 & 0.1864 \\
\hline 315 & 0.0839 \\
320 & 0.0180 \\
Total & 1 \\
\hline
\end{tabular}


The values for the term "EE x I" are constants, which were determined by Sayre et al. [24], and are shown in Table 2. To study the effects of UV radiation in SPF values degradation, all absorbance values were measured in every seven days during twenty-one days.

\section{Results and Discussion}

\section{Sun protective factor (SPF) value}

UV-A (320 to $400 \mathrm{~nm}$ ) of the UV region of the electromagnetic spectrum is the predominant source of harmful solar radiation then UV-B (290 to $320 \mathrm{~nm}$ ) and UV-C (200 to $290 \mathrm{~nm}$ ), which provokes the early aging of the skin by reaching to dermis and epidermis [25]. The SPF is extensively used term in expressing the efficacy of sunscreen, which is defined as the relation of UV energy required to produce a minimal erythema dose on protected skin to unprotected skin. Thus, the higher the SPF, the more effective is the product in preventing sunburn. The exposure to UV radiation affects the skin keratinocytes with inflammatory, metabolic, and proliferative responses which helps to attempt self-protection from and adaptation to UV-induced damage [26]. Effective and safe skin protection against damages induced by solar irradiation remains among the unsolved problems of modern dermatology and cosmetology [27].

Plants extracts are considered as valuable sources of anti-photo-aging and photo-protective agents for the development of cosmeceutical and topical pharmaceutical products these days [28-31]. Many studies support the synergic photo-protective effect among natural plant sources, able to exert synergic anti-photo-aging, anti-inflammatory, and antioxidant activities [32]. The determination of SPF values for all six samples was made through the UVvisible spectrophotometric method and the Mansur equation as described in material and methods. Among the analyzed samples, the methanol extract of $P$. benthamii has highest absorbance value and hence highest SPF value (34.97 \pm 0.25$)$ followed by $T$. linearis (24.98 \pm 0.60$)$, B. pacumbis $(24.02 \pm 0.15)$, and $M$. koenigii $(10.74 \pm 0.32)$. The SPF values of the plant extract were compared with commercial sunscreen (26.92 \pm 0.42$)$. Two plant extracts; $A$. racemosus and $M$. azedarach does not shows potent SPF value (Table 3 ).
Table 3: Sun protective factor (SPF)

Plants Sun protective factor $(\mathrm{SPF})$

\begin{tabular}{cc}
\hline A. racemosus (ST1) & $1.97 \pm 0.07$ \\
B. pacumbis (ST2) & $24.02 \pm 0.15$ \\
M. azedarach (ST3) & $8.20 \pm 0.12$ \\
M. koenigii (ST4) & $10.74 \pm 0.32$ \\
P. benthamii (ST5) & $34.97 \pm 0.25$ \\
T. linearis (ST6) & $24.98 \pm 0.60$ \\
\hline Commercial Sunscreen & $26.92 \pm 0.42$ \\
\hline
\end{tabular}

Sun protective factor (SPF) value degradation Natural substances are considered as a potential source of skin protection and sunscreen resources because of their absorption in the UV region [33] and their antioxidant activity [34]. Although the skin has the ability to deals against the UV induced oxidative stress, the chronic exposure to UV could generate unwarranted reactive oxygen species (ROS) that leads to oxidative damage causing diverse harmful effects in the skin [35]. The degradation of the substances itself is good for skin protection in the sense that they do not possess significant side effects on the skin they applied. The study was carried out under direct solar for 7, 14, and 21 days ( 3 weeks) which results in decreases in their SPF values in the exposition of samples to sunlight, revealing that sunscreen products are photosensitive in the range between $\lambda=290$ and $320 \mathrm{~nm}$ as expected. Our results revealed that the degradation of SPF value is directly correlated with sun exposure time (Figure 1). Our results also revealed that the $P$. benthamii extract has strong sun protection ability as compared with the standard sun screen.

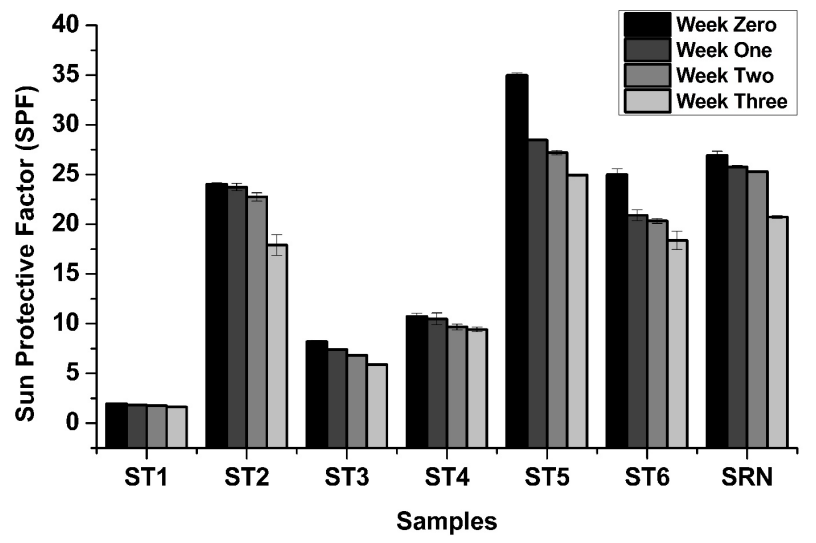

Figure 1: Sun protective factor (SPF) degradation 


\section{Conclusion}

Our results revealed that examined plant extracts have greater tendencies to absorb UV radiation and hence proven to have UV protective effect. Among analyzed plant extracts, $P$. benthamii, B. pacumbis, and $T$. linearis have highest sun protective factor and are comparable with the commercially available sunscreen lotions. Hence, these plants can be used as a natural sun protecting agent in sunscreen cosmetic products. Further identification of natural products from these plant species might increase the sun protective effect. Our laboratory is focusing on the identification of natural sun protective agents from these plants extract. Our results open up the possibilities of these plant extract for the developments of cosmetics products.

\section{Acknowledgement}

We are thankful to H-plant Pvt. Ltd., Nepal for the financial support and National Herbarium and Plant Laboratory, Nepal for plants identification and authorization.

\section{References}

1. M. Ichihashi, M. Ueda, A. Budiyanto, T. Bito, M. Oka, M. Fukunaga, K. Tsuru and T. Horikawa, UV-induced skin damage, Toxicology, 2003, 189, 21-39.

2. M. A. Ebrahimzadeh, R. Enayatifard, M. Khalili, M. Ghaffarloo, M. Saeedi and J.Y. Charati, Correlation between sun protection factor and antioxidant activity, phenol and flavonoid contents of some medicinal plants, Iranian Journal of Pharmaceutical Research, 2014, 13, 1041.

3. H. Lakhdar, K. Zouhair, K. Khadir, A. Essari, A. Richard, S. Seité and A. Rougier, Evaluation of the effectiveness of a broad spectrum sunscreen in the prevention of chloasma in pregnant women, Journal of the European Academy of Dermatology and Venereology, 2007, 21, 738-742.

4. L. Gaspar, P.M. Campos, Rheological behavior and the SPF of sunscreens, International Journal of Pharmaceutics, 2003, 250, 35-44.

5. A. Saija, A. Tomaino, D. Trombetta, A. De Pasquale, N. Uccella, T. Barbuzzi, D. Paolino and $\mathrm{F}$. Bonina, In vitro and in vivo evaluation of caffeic and ferulic acids as topical photoprotective agents, International Journal of Pharmaceutics, 2000, 199, 39-47.
6. P. Mehta, K. Chand, D. Narayanswamy, D. G. Beetner, R. Zoughi and W.V. Stoecker, Microwave reflectometry as a novel diagnostic tool for detection of skin cancers, IEEE Transactions on Instrumentation and Measurement, 2006, 55, 1309-1316.

7. P. N. Shenekar, P. S. Ukirade, S. D. Salunkhe, S. T. Sutar, C. Magdum, S. Mohite, S. G. Lokapure and S. M. Metri, In vitro evaluation of sun protection factor of fruit extract of Carica papaya L. as a lotion formulation, European Journal of Experimental Biology, 2014, 4, 44-47.

8. H. Vainio, A. B. Miller and F. Bianchini, An international evaluation of the cancer-preventive potential of sunscreens, International Journal of Cancer, 2000, 88, 838-842.

9. A.Ahmady, M.H.Amini,A. M. Zhakfar, G. Babak and M. N. Sediqi, Sun protective potential and physical stability of herbal sunscreen developed from Afghani medicinal plants, Turkish Journal of Pharmaceutical Sciences, 2020, 17, 285-292.

10. F. Afaq and H. Mukhtar, Botanical antioxidants in the prevention of photocarcinogenesis and photoaging, Experimental Dermatology, 2006, 15, 678-684.

11. S. H. Chermahini, F. A. A. Majid and M. R. Sarmidi, Cosmeceutical value of herbal extracts as natural ingredients and novel technologies in anti-aging, Journal of Medicinal. Plants Research, 2011, 5, 3074-3077.

12. N. Dayan, Skin Aging Handbook: an integrated approach to biochemistry and product development, William Andrew, 2008.

13. S.C. Thompson, D. Jolley and R. Marks, Reduction of solar keratoses by regular sunscreen use, $\mathrm{New}$ England Journal of Medicine, 1993, 329, 1147 1151.

14. K-H. Wang, R-D. Lin, F-L. Hsu, Y-H. Huang, H-C. Chang, C-Y. Huang and M-H. Lee, Cosmetic applications of selected traditional Chinese herbal medicines, Journal of Ethnopharmacology, 2006, 106, 353-359.

15. H. Smith, D. Armstrong, D. Holloway, L. Whittam, D. Basketter and J. McFadden, Skin irritation thresholds in hairdressers: implications for the development of hand dermatitis, British Journal of Dermatology, 2002, 146, 849-852. 
16. T. Aburjai and F. M. Natsheh, Plants used in cosmetics, Phytotherapy Research: An International Journal Devoted to Pharmacological and Toxicological Evaluation of Natural Product Derivatives, 2003, 17, 9871000.

17. A. J. Raj, S. Biswakarma, N. A. Pala, G. Shukla, M. Kumar, S. Chakravarty and R. W. Bussmann, Indigenous uses of ethnomedicinal plants among forest-dependent communities of Northern Bengal, India, Journal of Ethnobiology and Ethnomedicine, 2018, 14, 8.

18. D. M. Kasote, S. D. Jagtap, D. Thapa, M. S. Khyade and W. R. Russell, Herbal remedies for urinary stones used in India and China: a review, Journal of Ethnopharmacology, 2017, 203, 55-68.

19. M. Rajbhandari, R. Mentel, P. Jha, R. Chaudhary, S. Bhattarai, M. Gewali, N. Karmacharya, M. Hipper and U. Lindequist, Antiviral activity of some plants used in Nepalese traditional medicine, Evidence-Based Complementary and Alternative Medicine, 2009, 6, 517-522.

20. R. M. Kunwar, B. K. Nepal, H. B. Kshhetri, S. K. Rai and R. W. Bussmann, Ethnomedicine in Himalaya: a case study from Dolpa, Humla, Jumla and Mustang districts of Nepal, Journal of Ethnobiology and Ethnomedicine, 2006, 2, 27.

21. M. B. Rokaya, Z. Münzbergová and B. Timsina, Ethnobotanical study of medicinal plants from the Humla district of western Nepal, Journal of Ethnopharmacology, 2010, 130, 485-504.

22. I. Chiffelle, A. Huerta Fuentes and D. Lizana Rojas, Physical and chemical characterization of Melia azedarach L. fruit and leaf for use as botanical insecticide, Chilean Journal of Agricultural Research, 2009.

23. J. D. S. Mansur, M. Breder, M. Mansur and R. D. Azulay, [Determination of sun protection factor by specrophotometry] Determinação do fator de proteção solar por espectrofotometria, 1986.

24. R. M. Sayre, P. P. Agin, G. J. LeVee and E. Marlowe, A comparison of in vivo and in vitro testing of sunscreening formulas, Photochemistry and Photobiology, 1979, 29, 559-566.

25. E. A. Dutra, D. A. G. d.C. Oliveira, E.R.M. KedorHackmann and M.I.R.M. Santoro, Determination of sun protection factor (SPF) of sunscreens by ultraviolet spectrophotometry, Revista Brasileira de Ciências Farmacêuticas, 2004, 40, 381-385.

26. V. Kostyuk, A. Potapovich, D. Lulli, A. Stancato, C. De Luca, S. Pastore and L. Korkina, Modulation of human keratinocyte responses to solar UV by plant polyphenols as a basis for chemoprevention of non-melanoma skin cancers, Current Medicinal Chemistry, 2013, 20, 869879.

27. K. Scharffetter-Kochanek, M. Wlaschek, P. Brenneisen, M. Schauen, R. Blaudschun and J. Wenk, UV-induced reactive oxygen species in photo carcinogenesis and photoaging, Biological Chemistry, 1997, 378, 1247-1258.

28. R. Pallela, Y. Na-Young and S.-K. Kim, Antiphotoaging and photoprotective compounds derived from marine organisms, Marine Drugs, 2010, 8, 1189-1202.

29. D. Chanchal and S. Swarnlata, Herbal photoprotective formulations and their evaluation, The Open Natural Products Journal, 2009, 2.

30. N. Saewan and A. Jimtaisong, Natural products as photoprotection, Journal of Cosmetic Dermatology, 2015, 14, 47-63.

31. L.G. Korkina, W. Mayer and C. De Luca, Meristem plant cells as a sustainable source of redox actives for skin rejuvenation, Biomolecules, 2017, 7, 40.

32. M. Radice, S. Manfredini, P. Ziosi, V. Dissette, P. Buso, A. Fallacara and S. Vertuani, Herbal extracts, lichens and biomolecules as natural photo-protection alternatives to synthetic UV filters. A Systematic Review, Fitoterapia, 2016, 114, 144-162.

33. M.-C. Liu, C.-T. Lin, M.-D. Shau, Z.-S. Chen and M.-T. Chen, Studies on natural ultraviolet absorbers, Journal of Food and Drug Analysis, 1996, 4.

34. F. Bonina, M. Lanza, L. Montenegro, C. Puglisi, A. Tomaino, D. Trombetta, F. Castelli and A. Saija, Flavonoids as potential protective agents against photo-oxidative skin damage, International Journal of Pharmaceutics, 1996, 145, 87-94.

35. S. K. Katiyar and C. A. Elmets, Green tea polyphenolic antioxidants and skin photoprotection, International Journal of Oncology, 2001, 18, 1307-1313. 